\title{
Carbamazepine induced Stevens-Johnson Syndrome (SJS) due to missed history of mast cell activation triggered by methotrexate.
}

\author{
Tamer Zaalouk ${ }^{1}$, zouheir Bitar ${ }^{1}$, Osama Maadarani ${ }^{1}$, and Mohamed Elhabibi ${ }^{1}$ \\ ${ }^{1}$ Ahmadi Hospital
}

August 6, 2020

\begin{abstract}
Stevens-Johnson Syndrome (SJS) happen as a result of infection, side effects to medications or of unknown etiology. Carbamazepine is a common cause (SJS). Good history taking is crucial if clinically indicated treatment with carbamazepine. carbamazepine should be avoided with previous history of severe drug reaction like mast cell activation syndrome.
\end{abstract}

Carbamazepine induced Stevens-Johnson Syndrome (SJS) due to missed history of mast cell activation triggered by methotrexate.

Tamer Mohamed Zaalouk*, Zouheir Ibrahim Bitar, Ossama Sajeh Maadarani, Mohamed Alhabibie

Critical Care Unit, Ahmadi Hospital, Kuwait Oil Company P.O.Box 46468 , Postal code 64015 Fahaheel

Corresponding author.Email: tzaalouk@hkockw.com or forevertn@hotmail.com

Carbamazepine induced Stevens-Johnson Syndrome (SJS) due to missed history of mast cell activation triggered by methotrexate.

Key clinical Message Stevens-Johnson Syndrome (SJS) is serious conditions that happen as a result of infection, side eff

\section{CASE REPORT}

A 42-year-old-woman with history of methotrexate induced pruritis and severe skin reaction, She had ectopic pregnancy 2 years ago treated with methotrexate after which she developed severe stomatitis, leucopenia and severe inflammation of urinary bladder, diagnosed as mast cell activation syndrome at that time. Recently admitted with fever; generalised macular rash; buccal ulceration; and burning sensation in her eyes. the patient was admitted to critical care unit as a case of SJS. Further history revealed that she started treatment with carbamazepine 2 weeks before admission treating Trigeminal neuralgia. The medical history was otherwise unremarkable. On physical examination, there is erythema and painful erosions on both lips (fig 1), with several flaccid and ruptured bullae on the Rt hand, back, and legs. With generalized maculopapular rash with Target lesions all over the body in centrifugal distribution (fig 2-3). Patient complain of odynophagia but able to swallow some liquids. With involvement of genital mucosa. Nikolsky's sign was positive (Figure 4).

Laboratory investigations showed mild leukopenia, no eosinophilia, thrombocytopenia with mildly elevated Aspartate aminotransferase (AST), Alanine aminotransferase (ALT) and C-Reactive protein (CRP). No symptoms or signs of infection with negative blood, urine and sputum cultures. No skin biopsy was taken.

Patient admitted to critical care unit, Carbamazepine discontinued immediately, patient received intravenous 
fluid maintaining positive balance, nutritional support, Eye care and wound care.

Steroid treatment was given for 5 days in the form of 40 miligram methyl prednisolone daily. On the 10th day patient was discharged.

\section{Laboratory results}

WBCs (White blood count) $=3,600$

WBCs $($ White blood count $)=3,600 \mathrm{HB}($ Haemoglobin $)=13.4$ grams Platlets $=103,000$ Urea $=15$ miligram $/$ dl Creatinin

\section{DISCUSSION}

Stevens-Johnson syndrome (SJS) is a severe mucocutaneous reactions, most commonly triggered by medications, Infection and in $1 / 3$ of cases no cause was identified. There is extensive necrosis and detachment of the epidermis [1].

Mucous membranes are usually affected in more than $90 \%$ of cases. Both SJS and TEN are distinguished chiefly by severity, based upon the percentage of blisters and erosions [2,3].

Medications are main trigger of SJS especially allopurinol and anti-epileptic medications [4-5].

The pathology of Stevens-Johnson syndrome is incompletely understood. Studies suggested a cell-mediated reaction against keratinocytes leading to necrosis $[6]$.

Drugs can stimulate the immune system by binding to the major histocompatibility complex (MHC) class I and the T cell receptor, The hallmark of SJS is the keratinocyte necrosis, ranging from partial to full-thickness necrosis of the epidermis [7-8].

For patients with suspected drug induced SJS withdrawal of the offending agent may improve the prognosis. In a 1 observational study of 113 patients with SJS, early drug withdrawal reduced the risk of death by 30 percent for each day before the development of blisters and erosions [9]

The main lines of managment include fluid and electrolyte management,wound care, nutritional support, pain control,temperature management, treatment of infections [10-11].

There are no definitive therapies for SJS [12-13]. Several immunosuppressive or immunomodulating therapies have been used in clinical practice, including systemic corticosteroids, intravenous immune globulin (IVIG), cyclosporine, plasmapheresis, and anti-tumor necrosis factor (TNF) monoclonal antibodies.

None of these therapies have been adequately studied in randomized trials except thalidomide, which was found to be harmful [14]

The use of systemic corticosteroids in patients with SJS has not been evaluated in clinical trials and remains controversial [15].

Another immunologically medicated disorders is Mast cell activation syndrome (MCAS), which is one of Mast cell disorders present with signs and symptoms that are caused either by activation of mast cells or by mast cells infiltrating organs [16].

Mast cell activation syndrome (MCAS) was first proposed as a distinct idiopathic disorder in 2010 [17]. Subsequently, the definition of MCAS expanded to also include primary and secondary categories, making "mast cell activation syndrome" essentially an umbrella term that describes a clinical presentation, rather than a specific diagnosis [18].

In our case the patient was diagnosed earlier with mast cell activation syndrome with pruritis and severe skin reaction, two years later prescribed carbamazepine treating trigeminal neuralgia, the history of drug induced immunologically mediated mast cell activation with skin pruritis was missed and patient developed 
severe form of SJS. Good history taking is crucial if clinically indicated treatment with carbamazepine. We would like to alert all physicians that carbamazepine should be avoided in any patient with a previous history of drug reaction like mast cell activation syndrome.

\section{CONCLUSION}

Stevens-Johnson Syndrome (SJS) is very serious skin conditions. Carbamazepine is one of common medication that can cause (SJS). Good history taking is crucial if carbamazepine clinically indicated. Physicians should be alert to avoid carbamazepine in any patient with a previous history of drug reaction like mast cell activation syndrome.

\section{CONFLICT OF INTEREST}

None declared.

\section{FUNDING}

The authors received no financial support for the research, authorship, and/or publication of this article. This research was performed as part the authors duties in Kuwait oil Company,Kuwait.

\section{AUTHOR CONTRIBUTIONS}

Tamer Zaalouk wrote the article, Zouheir Ibrahim Bitar and Ossama S. Maadarani shared in the discussion and Mohamed Alhabibie collected data and revised the manuscript. All authors reviewed the final draft of the manuscript and approved its submission.

\section{REFERENCES}

1. Stern RS, Divito SJ. Stevens-Johnson Syndrome and Toxic Epidermal Necrolysis: Associations, Outcomes, and Pathobiology-Thirty Years of Progress but Still Much to Be Done. J Invest Dermatol 2017; $137: 1004$.

2. Bastuji-Garin S, Rzany B, Stern RS, et al. Clinical classification of cases of toxic epidermal necrolysis, Stevens-Johnson syndrome, and erythema multiforme. Arch Dermatol 1993; 129:92.

3. Roujeau JC. Stevens-Johnson syndrome and toxic epidermal necrolysis are severity variants of the same disease which differs from erythema multiforme. J Dermatol 1997; 24:726.

4. Wetter DA, Camilleri MJ. Clinical, etiologic, and histopathologic features of Stevens-Johnson syndrome during an 8-year period at Mayo Clinic. Mayo Clin Proc 2010; 85:131.

5. Khalaf D, Toema B, Dabbour N, Jehani F. Toxic epidermal necrolysis associated with severe cytomegalovirus infection in a patient on regular hemodialysis. Mediterr J Hematol Infect Dis 2011; 3: e2011004.

6. Correia O, Delgado L, Ramos JP, et al. Cutaneous T-cell recruitment in toxic epidermal necrolysis. Further evidence of CD8+ lymphocyte involvement. Arch Dermatol 1993; 129:466.

7. Ko TM, Chung WH, Wei CY, et al. Shared and restricted T-cell receptor use is crucial for carbamazepine-induced Stevens-Johnson syndrome. J Allergy Clin Immunol 2011; 128:1266.

8. Rzany B, Hering O, Mockenhaupt M, et al. Histopathological and epidemiological characteristics of patients with erythema exudativum multiforme major, Stevens-Johnson syndrome and toxic epidermal necrolysis. Br J Dermatol 1996; 135:6.

9. Naegele D, Sekula P, Paulmann M, Mockenhaupt M. Incidence of Stevens-Johnson syndrome/toxic epidermal necrolysis: results of 10 years from the German Registry. Pharmacoepidemiol Drug Saf 2017; 26(Supp 2):3.

10. Sekula P, Dunant A, Mockenhaupt M, et al. Comprehensive survival analysis of a cohort of patients with Stevens-Johnson syndrome and toxic epidermal necrolysis. J Invest Dermatol 2013; 133:1197.

11. Mittmann N, Knowles SR, Koo M, et al. Incidence of toxic epidermal necrolysis and Stevens-Johnson Syndrome in an HIV cohort: an observational, retrospective case series study. Am J Clin Dermatol 2012; 13:49. 
12. Valeyrie-Allanore L, Poulalhon N, Fagot JP, et al. Stevens-Johnson syndrome and toxic epidermal necrolysis induced by amifostine during head and neck radiotherapy. Radiother Oncol 2008; 87:300.

13. Wolkenstein P, Carrière V, Charue D, et al. A slow acetylator genotype is a risk factor for sulphonamideinduced toxic epidermal necrolysis and Stevens-Johnson syndrome. Pharmacogenetics 1995; 5:255.

14. Slatore CG, Tilles SA. Sulfonamide hypersensitivity. Immunol Allergy Clin North Am 2004; 24:477.

15. Rotunda A, Hirsch RJ, Scheinfeld N, Weinberg JM. Severe cutaneous reactions associated with the use of human immunodeficiency virus medications. Acta Derm Venereol 2003; 83:1.

16. Theoharides TC, Valent P, Akin C. Mast Cells, Mastocytosis, and Related Disorders. N Engl J Med $2015 ; 373: 163$.

17. Akin C, Valent P, Metcalfe DD. Mast cell activation syndrome: Proposed diagnostic criteria. J Allergy Clin Immunol 2010; 126:1099.

18. Valent P, Akin C, Arock M, et al. Definitions, criteria and global classification of mast cell disorders with special reference to mast cell activation syndromes: a consensus proposal. Int Arch Allergy Immunol 2012; 157:215. 


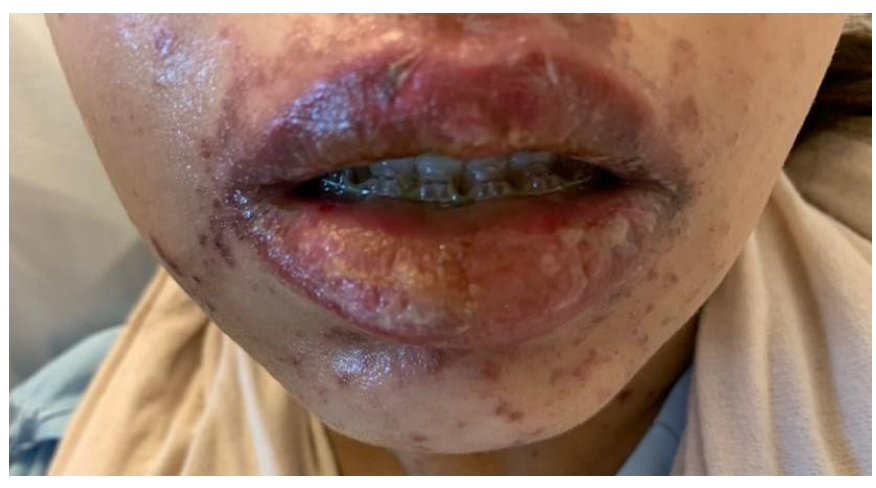

Figure 1

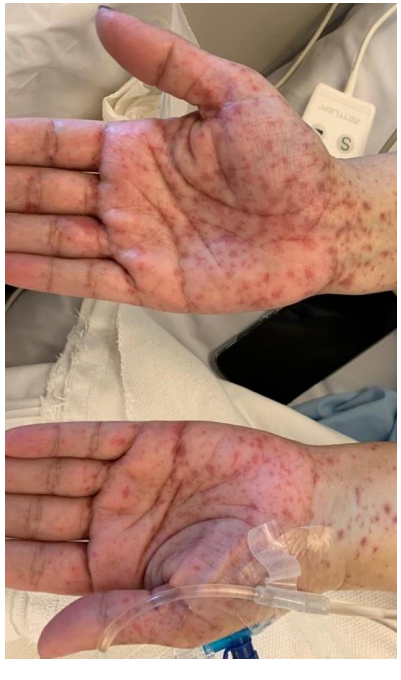

Figure 2 